\title{
A EUROPEAN SURVEY ON PUBLIC HEALTH POLICIES FOR MANAGING CASES OF MENINGOCOCCAL DISEASE AND THEIR CONTACTS
}

\author{
M Hoek $^{1,2}$, G Hanquet ${ }^{3}$, S Heuberger ${ }^{4}$, P Stefanoff5, P Zucs ${ }^{6}$, M Ramsay ${ }^{2}$, J Stuart (james.stuart@hpa.org.uk)², on behalf of the \\ European Union Invasive Bacterial Infections Surveillance Network (EU-IBIS) ${ }^{7}$ \\ 1. European Programme for Intervention Epidemiology Training \\ 2. Health Protection Agency, London, United Kingdom \\ 3. Scientific Institute of Public Health, Brussels, Belgium \\ 4. Austrian Agency for Food and Health Safety, Graz, Austria \\ 5. National Institute of Hygiene, Warsaw, Poland \\ 6. Federal Office of Public Health, Berne, Switzerland \\ 7. European Union Invasive Bacterial Infections Surveillance Network (EU-IBIS)
}

In 2007, a European survey was conducted to compare national policies on public health management of cases of meningococcal disease and their contacts. An electronic questionnaire was sent to 27 national public health institutes; 22 countries responded (response rate $81 \%$ ). The results of the survey revealed differences in definitions of close contacts and prophylactic regimens between countries. These differences can be attributed to a lack of evidence on optimal prevention and treatment strategies. The development of guidance for best practice in priority areas, based on evidence or consensus, is therefore recommended.

\section{Introduction}

Meningococcal disease is a severe illness with high morbidity and mortality. The relatively high risk of further cases among close contacts of a primary case is well established $[1,2]$. Close contacts may be the source of the organism that caused disease in the index case, or may have recently acquired the organism from another contact or from the index case [3]. Applying antibiotic treatment to close contact persons to eliminate meningococcal carriage reduces the risk of further cases [3], but evidence is lacking in many other areas of policy, leading to difficulties in adopting a consistent approach $[4,5]$. We conducted a survey to map the variations in public health management policies for meningococcal disease across Europe.

\section{Methods}

We prepared a questionnaire to collect information on case and contact definitions, the use of chemoprophylaxis and vaccination, and communication about changes in the guidelines. In April 2007, the questionnaires were sent by email to public health representatives of the European Union Invasive Bacterial Infection Surveillance network (EU-IBIS, http://www.euibis.org) and the European Meningococcal Disease Society (EMGM, http://www. emgm.eu) in 27 countries in Europe. The responses were analysed using Microsoft Excel.

\section{Results}

Of the 27 countries represented in EU-IBIS and EMGM, the questionnaires were completed and returned by $22(81 \%)$ : Austria, Belgium, the Czech Republic, Denmark, Estonia, Finland,
France, Germany, Hungary, Iceland, Ireland, Lithuania, Malta, the Netherlands, Norway, Poland, Romania, Slovakia, Spain, Sweden, Switzerland, and the United Kingdom. Two questionnaires were returned from Belgium and six from Austria, reflecting subnational political structures. For analysis, the two questionnaires from Belgium were included separately, but only the questionnaire returned from the national reference laboratory was taken as representing Austrian national policy, bringing the denominator to 23.

\section{Definition of close contacts}

All countries recommended chemoprophylaxis for close contacts of a case. However, we found differences in the definitions of cases and close contacts in use for applying control measures (Tables 1 and 2). The trace-back period for close contacts varied from seven days (14/23) to 10 days (7/23) or no particular period at all (2/23). There was also variation in the criteria of duration and proximity of exposure to a case used to define a close contact, especially evident in contacts on public transport (Table 3).

\section{Chemoprophylaxis}

Ciprofloxacin, rifampicin and ceftriaxone were the antibiotics most frequently recommended in adults (aged 18 years or older). In those under 18 years, the most commonly recommended antibiotics were rifampicin and ciprofloxacin. The recommended age for prescribing ciprofloxacin varied widely. In some countries ciprofloxacin was prescribed for newborns, while in others the use of ciprofloxacin under the age of 18 years was not recommended. Three countries recommended the use of azithromycin in children, and one in adults (Table 4). Giving antibiotics to a patient with suspected meningococcal disease prior to hospitalisation was not a common practice. Nine countries (39\%) recommended an injection of penicillin as soon as a meningococcal infection was suspected. Chemoprophylaxis in a case before discharge from hospital to eradicate carriage was recommended by 11 countries unless the case had been treated with a cephalosporin (third generation). Four of these countries specifically mentioned ceftriaxone. Twelve countries did not specifically recommend the use of antibiotics to eradicate carriage in a case prior to discharge from hospital. 


\section{Vaccination}

Seventeen countries (74\%) recommended vaccination in addition to chemoprophylaxis for close contacts if illness in the case was due to a vaccine-preventable serogroup. Nine countries had defined epidemiological thresholds to commence local or regional vaccination campaigns during outbreaks of meningococcal disease. The most commonly used thresholds were 10 or 40 cases per 100,000 population, or three or more cases of the same serogroup within three months in a defined age group of the population of a defined region. Eight countries included serogroup $C$ conjugate vaccine in the national childhood vaccination programme.

\section{Communication issues}

Changes and amendments in the national or sub-national guidelines case definitions, treatment, and prevention were mainly communicated by publishing the changes on the websites of the national authorities. Six countries commented on the lack of efficient communication of changes in the guidelines to those responsible for implementation.

T A B L E 1

Case definition criteria for meningococcal disease. European survey on public health policies for managing cases of meningococcal disease and their contacts, $2007(n=23)$

\begin{tabular}{|l|c|}
\hline Case definition criteria & $\begin{array}{c}\text { Number of } \\
\text { countries } \\
(\% \text { of total) }\end{array}$ \\
\hline Isolation of Neisseria meningitidis from sterile site & $22(96 \%)$ \\
\hline Isolation of meningococcal DNA from sterile site & $20(87 \%)$ \\
\hline Isolation of Gram-negative diplococci from sterile site & $20(87 \%)$ \\
\hline Isolation of antigen from sterile site & $19(83 \%)$ \\
\hline Clinically compatible & $16(70 \%)$ \\
\hline Purpura fulminans & $16(70 \%)$ \\
\hline Official notification & $11(48 \%)$ \\
\hline Detection of high titre in convalescent serum & $6(26 \%)$ \\
\hline
\end{tabular}

T A B L E 3

Duration and proximity criteria for administering chemoprophylaxis to fellow passengers. European survey on public health policies for managing cases of meningococcal disease and their contacts, $2007(n=23)$

\begin{tabular}{|l|c|}
\hline $\begin{array}{l}\text { Criteria for chemoprophylaxis in fellow } \\
\text { passengers }\end{array}$ & $\begin{array}{c}\text { Number of countries } \\
\text { (\% of total) }\end{array}$ \\
\hline Time of travel: & $2(9 \%)$ \\
\hline Four hours or more & $1(4 \%)$ \\
\hline Seven hours or more & $3(13 \%)$ \\
\hline Eight hours or more & $1(4 \%)$ \\
\hline Overnight travel & $16(70 \%)$ \\
\hline Not specified & $2(9 \%)$ \\
\hline Proximity to case: & $1(4 \%)$ \\
\hline Next to case & $2(9 \%)$ \\
\hline Same row, row in front and back & $15(65 \%)$ \\
\hline Seated “close to case” & \\
\hline Undefined & \\
\hline
\end{tabular}

\section{Discussion}

The different approaches to risk reduction, the use of antibiotics, patient care and the implementation of control measures detected in this study may arise from uncertainties about the effectiveness of public health interventions, variations in heath care systems and differences in attitudes to risk management. Nearly all countries recommended the use of ciprofloxacin, rifampicin and ceftriaxone for chemoprophylaxis in close contacts. These are all considered effective at eradicating carriage [6], and at reducing attack rates in close contacts [3]. The recommended use of antibiotics in children and pregnant women showed more variability both in a lower age limit for children and in the type of antibiotic. This variation may reflect concerns about recommending antibiotics if not licensed for chemoprophylaxis of meningococcal disease in pregnancy or young children, as well as the availability of paediatric formulations. Further research is needed to understand the reasons for such variability.

There is uncertainty about how to define close contacts among fellow passengers on long plane, train or bus trips. How close and for how long does a fellow passenger have to be seated next to someone

T A B L E 2

Definitions of close contacts. European survey on public health policies for managing cases of meningococcal disease and their contacts, $2007(n=23)$

\begin{tabular}{|l|c|}
\hline Criteria for close contacts & $\begin{array}{c}\text { Number of } \\
\text { countries } \\
(\% \text { of total) }\end{array}$ \\
\hline People sharing the same household & $23(100 \%)$ \\
\hline People with equivalent level of close contact & $22(96 \%)$ \\
\hline People sharing cups or glasses & $9(39 \%)$ \\
\hline Kissing on mouth & $10(43 \%)$ \\
\hline Kissing on cheek & $3(13 \%)$ \\
\hline
\end{tabular}

T A B L E 4

Antibiotics recommended in chemoprophylaxis by age and in stage of pregnancy. European survey on public health policies for managing cases of meningococcal disease and their contacts, $2007(n=23)$

\begin{tabular}{|l|c|c|c|c|}
\hline & $\begin{array}{c}\text { Adults } \\
(\mathbf{1 8 +})\end{array}$ & $\begin{array}{c}\text { Children } \\
(<\mathbf{1 8})\end{array}$ & $\begin{array}{c}\text { Pregnancy } \\
\mathbf{1}^{\text {st }} \\
\text { trimester) }\end{array}$ & $\begin{array}{c}\text { Pregnancy } \\
\left(2^{\text {na }} \text { \& } 3^{\text {rd }}\right. \\
\text { trimester }\end{array}$ \\
\cline { 2 - 5 } & $\mathrm{n}(\%)$ & $\mathrm{n}(\%)$ & $\mathrm{n}(\%)$ & $\mathrm{n}(\%)$ \\
\hline Rifampicin & $14(61 \%)$ & $16(70 \%)$ & $4(17 \%)$ & $5(22 \%)$ \\
\hline Ciprofloxacin & $20(87 \%)$ & $6(26 \%)$ & 0 & 0 \\
\hline Ceftriaxone & $13(57 \%)$ & $7(30 \%)$ & $12(52 \%)$ & $11(48 \%)$ \\
\hline Azithromycin & $1(4 \%)$ & $3(13 \%)$ & $2(9 \%)$ & $1(4 \%)$ \\
\hline
\end{tabular}


with meningococcal disease to be eligible for chemoprophylaxis? The most commonly used definition is anyone sitting in the rows in front or behind the case for a period of seven hours or longer. However, periods varied between four and 10 hours, and some countries did not consider fellow travelers for chemoprophylactic treatment at all. The United States' Centers for Disease Control and Prevention recommend prophylaxis if air-travel-associated exposure lasts more than eight hours, but there is little or no evidence to quantify the risks [7]. One Australian report describes two cases of meningococcal disease among passengers sitting several rows apart on the same plane, both with dates of onset 3-5 days after the flight [8]. Transmission on board the airplane may have occurred from an asymptomatic carrier, as no direct contact occurred between the passengers. Another area of variation was whether mouth kissing or sharing drinks justify chemoprophylaxis; the former but not the latter may be an important risk factor for transmission $[9,10]$.

The administration of a single dose of penicillin prior to hospitalisation was recommended in one third of the countries surveyed. The literature on this topic is difficult to interpret. Some observational studies report a lower case fatality among those who received a single dose of penicillin prior to hospitalisation, while others show a higher risk of death [11]. There is likely to be confounding related to severity of illness in such observational studies as physicians will be influenced by clinical assessment in making decisions on treatment [11]. Other differences seen in the national guidelines regarded the administration of chemoprophylaxis to a patient before discharge from hospital. Most countries recommended vaccination in addition to chemoprophylaxis for contacts if illness was due to a vaccine-preventable serogroup. This policy is supported by a recent review of effectiveness (M. Hoek, article in submission).

Six countries remarked that changes in national policies were not communicated efficiently or effectively. It is possible that other countries face similar difficulties, and efforts should be made to ensure that changes in national or sub-national guidelines are communicated quickly and effectively to those responsible for case management and prevention.

The incidence of meningococcal disease in Europe has decreased over the last decade following the introduction of serogroup $\mathrm{C}$ conjugate vaccines. However, there are no imminent prospects for the introduction of serogroup $B$ vaccines. The severity and rapid progression of meningococcal disease and the high risk of infection among contacts indicate a continuing need for clear public health policies. The differences between various national policies revealed in this study reflect areas of uncertainty about the effectiveness of public health interventions. The survey was based on information about national policies as reported by public health expert representatives, but several respondents also commented on varying interpretations of national guidelines at sub-national level.

At a meeting of the European Monitoring Group on Meningococci in 2007, there was strong support for an assessment of priority areas for guidance, a review of the evidence to support policy, and the development of consensus around guidance for best practice.

\section{Acknowledgements}

We would like to thank all EU-IBIS participants (http://www.euibis.org/ meningo/euibis_partners_meningo.htm) and members of the European Meningococcal Disease Society (http://emgm.eu who) contributed to the discussion on the survey results:

Lucia Pastore Celentano, Reinhild Strauss, Sigrid Heuberger, Germaine Hanquet, Suzana Bukovski, Pavla Krizova, Michael Howitz, Kuulo Kutsar, Petri Ruutu, Isabelle Parent du Châtelet, Wiebke Hellenbrand, Jenny Kourea-Kremastinou, Katalin Krisztalovics, Thorolfur Gudnason, Suzanne Cotter, Marta Ciofi, Irina Lucenko, Grazina Rimseliene, Jackie Maistre Melillo, Sabine de Greeff, Øistein Løvoll, Pawel Stefanoff, Laurinda Queirós, Marina Pana, Izika Korolesa, Margareta Sláciková, Alenka Kraigher, Rosa Cano Portero, Margareta Löfdahl, Phillip Zucs and Mary Ramsay.

\section{References}

1. De Wals P, Hertoghe L, Borlee-Grimee I, De Maeyer-Cleempoel S, ReginsterHaneuse G, Dachy A, et al. Meningococcal disease in Belgium. Secondary attack rate among household, day-care nursery and pre-elementary school contacts. J Infect 1981;3(suppl 1):53-61.

2. Munford RS, Taunay Ade E, de Morais JS, Fraser DW, Feldman RA. Spread of meningococcal infection within households. Lancet. 1974;1(7869):1275-8.

3. Purcell B, Samuelsson S, Hahne S, Ehrhard I, Heuberger S, Camaroni I, et al. Effectiveness of antibiotics in preventing meningococcal disease after a case: systematic review. BMJ. 2004;328(7452):1339.

4. Begg N. Policies for public health management of meningococcal disease. $J$ Epidemiol Community Health. 1999;53(9):516.

5. Stuart JM. Managing outbreaks, the public health response. In: Pollard AJ, Maiden MCJ, editors. Methods in molecular medicine. Meningococcal disease: methods and protocols. Totowa, NJ: Humana Press Inc; 2001. p. 257-72.

6. Fraser A, Gafter-Gvili A, Paul M, Leibovici L. Antibiotics for preventing meningococcal infections. Cochrane Database Syst Rev. 2006;(4):CD004785.

7. CDC. Exposure to patients with meningococcal disease on aircrafts - United States, 1999-2001. MMWR 2001;50:485-9.

8. O'Connor BA, Chant KG, Binotto E, Maidment CA, Maywood P, McAnulty JM. Meningococcal disease - probable transmission during an international flight. Commun Dis Intell 2005:29(5):312-4.

9. Tully J, Viner RM, Coen PG, Stuart JM, Zambon M, Peckham C, et al. Risk and protective factors for meningococcal disease in adolescents: matched cohort study. BMJ. 2006;332(7539):445-50.

10. Orr HJ, Gray SJ, Macdonald M, Stuart JM. Saliva and meningococcal transmission. Emerg Infect Dis. 2003;9(10):1314-5.

11. Hahné SJ, Charlett A, Purcell B, Samuelsson S, Camaroni I, Ehrhard I, et al. Effectiveness of antibiotics given before admission in reducing mortality from meningococcal disease: systematic review. BMJ. 2006;332(7553):1299303.

This article was published on 6 March 2008.

Citation style for this article: Hoek M, Hanquet G, Heuberger S, Stefanoff P, Zucs P, Ramsay $M$, Stuart J, on behalf of the European Union Invasive Bacterial Infections Surveillance Network (EU-IBIS). A European survey on public health policies for managing cases of meningococcal disease and their contacts. Euro Surveill. 2008;13(10):pii=8060. Available online: http://www.eurosurveillance.org/ViewArticle.aspx?ArticleId $=8060$ 